\title{
Review of Network Economics
}

Volume 9, Issue 2

2010

Article 2

\section{Is the Internet Bad News? The Online News Era and the Market for High-Quality News}

Paul Frijters, University of Queensland

Malathi Velamuri, Victoria University of Wellington

\section{Recommended Citation:}

Frijters, Paul and Velamuri, Malathi (2010) "Is the Internet Bad News? The Online News Era and the Market for High-Quality News," Review of Network Economics: Vol. 9: Iss. 2, Article 2. DOI: $10.2202 / 1446-9022.1187$ 


\title{
Is the Internet Bad News? The Online News Era and the Market for High-Quality News
}

\author{
Paul Frijters and Malathi Velamuri
}

\begin{abstract}
We review and model the impact of the internet on the production and uptake of high-quality news. Our review of trends in the market for news suggests three stylized facts: i) particular quality news markets are dominated by merely a few providers, ii) demand for quality news appears stable, but provision of news has become specialized; mainstream news is decoupled from quality news, and iii) the dominant business model of internet news mirrors that of radio, television, and newspapers in that costs of news production are recouped via advertising. We build a stylized model that rationalizes these facts. Our model captures three conflicting effects: (1) economies of scale in the production of news lead to monopolies on particular markets, (2) easy access to information on the internet makes it cheaper to provide high-quality news and to disseminate it via the web, which increases the production of such news; and (3) the existence of bloggers and news aggregators who recycle the stories of news-providers reduces the effective property rights of high-quality news producers, thus forcing the business model of the internet to be advertising-based. For the most likely cases, our model would imply that the internet does not constitute bad news for the provision and uptake of quality news.
\end{abstract}

KEYWORDS: news quality, internet, monopolies, search costs, advertising

Author Notes: We thank Paul Calcott, Andrew Leigh and Matthew Wennersten for comments and helpful suggestions. We remain responsible for all errors. 
"All the bloggers who exist to comment on us, the Googles and Yahoo!s ... who rely on what we cover in the Middle East, who rely on what we write about in California, and the nation, and Washington; they wouldn't exist if we didn't. Our economic model is, obviously, threatened. But if we disappeared tomorrow, they might have to reinvent something that looks like us." Dean Baquet, Editor, Los Angeles Times, quoted in "What you should know about the Newspaper Industry”, by Jonathan Jones, Feb 27, 2007.

\section{Introduction}

The production and dissemination of 'news' has changed dramatically in the developed world since the mid-twentieth century. New media platforms have emerged, there have been significant regulatory changes and news corporations have conglomerated. Popular opinion holds that this rapid transformation of the industry, by facilitating concentration of ownership, has led to a deterioration in the quality of news offered by the mainstream media and reduced the diversity of opinions expressed. ${ }^{1}$ Opinion polls indicate a falling public trust in the news media. ${ }^{2}$ Table 1 captures this trend; over time, there has been a gradual erosion in the share of news audience that views mainstream news outlets favorably, with local TV news, network TV news and newspapers receiving the harshest criticism. Hume (1996) contends that while public confidence in most institutions has diminished in the United States, journalism has fared the worst.

In the current digital era, news has gone online and comes in various forms simultaneously including television, radio, podcasts, blogs etc., and we are witnessing the emergence of a world market for news. Since the late 1990s, significant increases in broadband penetration in households has allowed a disenchanted public to move away from mainstream news sources and increasingly rely on the internet as the main source of news. News suppliers have followed suit, taking their content online and making it freely available to the public. ${ }^{3}$ Ironically, news suppliers point to the online news model as a culprit for falling standards in the news industry.

Our starting quote above is by a media insider who clearly believes that online commentators (bloggers) and news aggregation sites effectively steal the news

\footnotetext{
${ }^{1}$ See, for instance, McChesney (1999), Hume (1996) and Shah (2007)

${ }^{2}$ See the Pew Report (2007), "Views of Press Values and Performance: 1985-2007”, and Hume (1996).

${ }^{3} \mathrm{~A}$ few outlets charge customers for viewing their content but the majority now allow free access.
} 
Review of Network Economics, Vol. 9 [2010], Iss. 2, Art. 2

Table 1: News Media Favourability, 1985-2007

\begin{tabular}{|c|c|c|c|c|c|c|c|}
\hline $\begin{array}{l}\text { Favorable } \\
\text { opinion of }\end{array}$ & 1985 & 1992 & 1997 & 2001 & 2005 & 2007 & $\begin{array}{c}\text { 2001-'07 } \\
\text { change }\end{array}$ \\
\hline & $\%$ & $\%$ & $\%$ & $\%$ & $\%$ & $\%$ & $\%$ \\
\hline Local TV news & 89 & $91 * *$ & 84 & 83 & 79 & 79 & -4 \\
\hline Daily newspapers & 88 & 81 & 79 & 82 & 80 & 78 & -4 \\
\hline Cable TV news+ & $91^{*}$ & 95 & $86 * * *$ & 88 & 79 & 75 & -1.3 \\
\hline Network TV news & 89 & 86 & 76 & 76 & 75 & 71 & -5 \\
\hline Major national papers & 81 & 81 & 67 & 74 & 61 & 60 & -1.4 \\
\hline \multicolumn{8}{|c|}{$\begin{array}{l}\text { Source:PEW (2007), "Internet News Audience Highly Critical of News Organiza- } \\
\text { tions", Apr } 9 \\
\text { Note: Percentages based on those who could rate each. } \\
* 1987 ; * * 1991 ; * * * 1998 \\
+ \text { In } 1989 \text { and } 1992 \text {, the question asked only about CNN. In } 1998 \text { and 2001, the } \\
\text { cable news question listed CNN and MSNBC as examples. In } 2005 \text { and 2007, the } \\
\text { Fox news channel was included as well. }\end{array}$} \\
\hline
\end{tabular}

gathered by professional news-gatherers and that this free-riding affects their longterm prospects for survival. Many commentators share this view and assert that these activities spell the end of serious news gathering, as it is now cheaper to recycle someone else's news than generate original content. Another complaint by insiders is that the internet, and other new technologies, have reduced news quality by increasing the job scope of journalists:

“...they say you've not only got to write the story, you've got to do the audio version, the video version, you've got to do vodcasts and podcasts, that all takes more time as well and divides your concentration. So that the quality of the work is going down even though the amount and the variation of the product is increasing." (Nick Davies, Journalist and author, commenting on current journalistic standards, in an interview for the 7.30 Report for the Australian Broadcasting Corporation, 27/08/2008)

Despite the clamor about falling standards in the media, there has been no systematic investigation of the claim that the internet and related technologies have affected the provision of high-quality news. This paper seeks to examine that claim. Specifically, we investigate whether the internet era has reduced the demand and/or supply of high-quality news. We examine longer-term trends in the media industry 
preceding the online news era to distinguish secular trends from developments that can be attributed to the internet and related technologies. Distilling the historical information into a set of stylized facts, we model the impact of the internet on the uptake of high-quality news. 4

Our simple model captures three conflicting effects of the internet. The first is that easy access to information on the internet makes it cheaper to provide highquality news and to disseminate it via the web, which increases the production of such news. The second is that the existence of bloggers and news aggregators who recycle the stories of news-providers reduces the effective property rights of the high-quality news producers, thus reducing their incentives to invest in such news production. The third is that the internet has reduced the search costs of finding customers who generate the advertising revenue. Our model shows the conditions under which these combined effects lead to a long-term reduction or expansion in the provision of quality news. In isolation of the third effect, the second effect dominates the first, in the long-run: the production of high-quality news, whose costs do not go down at the same rate as the cost of information exchange on the internet, only survives in large markets. However, the third effect makes any highquality news provision that attracts a minimum level of customers commercially viable, even in the absence of property rights.

There is a small literature on the impact of the internet on media bias, on product variety and product positioning, and on the composition of news consumers for various sources of news. To our knowledge, this paper is the first to examine the effect of the internet news era on the provision and uptake of high-quality news. This is an issue of considerable importance, as an independent and critical media industry is a cornerstone of participatory democracy. As such, any development that affects the credibility of this industry has serious implications for the preservation of an informed citizenry.

Section 2 provides a brief description of the structure of the U.S. media industry and of major developments in the industry since the mid-twentieth century; Section 3 presents a concise literature review on trends in news quality over time, and synthesizes the findings into a list of stylized facts; Section 4 describes the simple theoretical model; Section 5 concludes.

\footnotetext{
${ }^{4}$ While perceptions of news quality can be fairly subjective and difficult to define, for our purposes, high-quality news refers to original reporting involving the collection and verification of facts, and a clear and concise analysis of the same. Typically, the generation of high-quality news involves investments of time and money.
} 


\section{Background - Media Industry in the U.S. and me- dia concentration}

Newspapers and radio dominated the news industry for the first half of the twentieth century. Robinson (2007) classifies the second half of the twentieth century in terms of the dominant news medium of the decade: the era of network news began in the 1960s with the advent of television and dominated the news scene up until the 1980s; the 1990s was the decade of Cable news characterized by 24-hour news broadcasts, dominated largely by $\mathrm{CNN}$; and the current decade marks the era of digital or online news, facilitated by the world wide web.

Successive waves of innovation provided more types of news products to consumers, with the long-term trend seeing technologies that reduced the dissemination costs of news, thus allowing for larger audiences to be served. In addition to changing technologies and institutions, the regulatory environment pushed the industry towards consolidation of news sources, challenging the viability of smaller media players. 5

Economists have long recognized that news provision is a textbook case of a natural monopoly, particularly for print media. News itself is a public good in that it can be copied without dilution once produced and it is hard to exclude consumers from it. News dissemination is also subject to increasing returns to scale, because of scale economies in bulk printing, and the classic properties of distribution networks. Early papers by Reddaway (1963) and Rosse (1967, 1970) and by Dertouzos and Trautman (1990) found strong evidence of the existence of scale economies in the newspaper industry. ${ }^{6}$ These characteristics imply that news provision will tend towards monopolies who have to recoup costs indirectly with advertising rather than circulation. The print media industry therefore invariably charges low cover prices for its products. ${ }^{7}$

\footnotetext{
${ }^{5}$ See Neiva (1995) for an account of the technological and institutional changes that pushed the U.S. newspaper industry towards consolidation; Berry and Waldfogel (1996) for regulatory changes affecting radio; Einstein (2004) and McEwen (2007) for regulatory changes in television; Gomery (2002) on regulation banning newspaper-broadcast cross-ownership; and " 4 advances that set News Back" (http://thefutureofnews.com/vision-future/advances/)

${ }^{6}$ Kaiser and Wright (2006) provide evidence of scale economies in the magazine industry in Germany.

${ }^{7}$ Radio also relied almost exclusively on subsidies and advertising since it was basically impossible to make people pay directly for radio reception. In the early days of television, advertisers bore the full cost of broadcasting, allowing consumers costless access to news throughout the day. Later on, with the advent of cable, it became possible for some specialized news channels to charge for news directly though advertising remained the dominant source of revenue for television right up to this day.
} 
The traditional reliance on advertising in all the news media means that the quote we started this paper with is slightly misleading: historically, the viability of the news industry has not relied on making people pay for actual news, but rather on persuading consumers to consume their news from the original news provider, allowing the provider to recoup costs via advertising. In principle, it is hard to see the fundamental difference that the internet has made to this reality: as long as providers can package their news and persuade consumers to get their news from the original source, they can still reap the advertising revenue that goes with it.

From the late 1990s until recently, the economic model adopted by the online media industry did indeed rely almost solely on advertising revenue. Advertisers supported the migration of news content online by moving their business online as well. However, in contrast to the traditional model, the principal beneficiaries of online advertising revenue have not been the content-creators but the web portals, search engines and news aggregators that relied on content-creators for news (Isaacson, 2009). From an economic point of view, these search engines and news aggregators are intermediaries that skim off the rents created by news provision.

Table 2 presents the shift in advertising shares between 2006 and 2007 at 17 major media companies, including Google, Yahoo, Microsoft, Time Warner, Disney, Viacom, CBS and Clear Channel. These companies span the online, TV, print, radio and outdoor advertising sectors. The table reveals that the combined advertising revenue of these 17 companies grew by $6 \%$ between the second quarters and $8 \%$ between the third quarters of 2006-'07. Offline revenue grew by less than $1 \%$ over the same periods, even after the inclusion of affiliate fees and global revenue at CBS, Viacom and News Corp. Online advertising revenue contributed 26\% and $30 \%$ to this growth in the second and third quarters respectively. One would expect the scope for such rent-skimming to reduce over time as consumers become more discerning in their search for news, and producers come up with strategies to attract consumers directly to their websites. ${ }^{8}$ Nevertheless, the downturn in the advertising industry in general, and internet advertising in particular since 2008, has exposed the vulnerability of this model to changes in economic conditions (Mutter, 2009).

\section{News quality in recent times}

Currently, five major companies dominate most of the media (Bagdikian, 2004). These companies are entertainment conglomerates that have vertically integrated

\footnotetext{
8"If visitors come from Google to stories deep in the paper and then leave, Google gets the dollars and we get only cents, but if we can bring them in through the front page we can charge Û19,000 [\$25,000] for a 24-hour banner ad." (Sverre Munck, executive vice-president of international business for Schibsted, a Norwegian newspaper firm, quoted in the Economist, 2006)
} 
Review of Network Economics, Vol. 9 [2010], Iss. 2, Art. 2

Table 2: U.S. Advertising Revenue (US\$ Millions) at 17 Major Media Companies by Sector (2006-'07)

\begin{tabular}{|l|l|l|l|l|l|l}
\hline \hline Ad Revenue & $\begin{array}{l}\text { Qtr2 } \\
2006\end{array}$ & $\begin{array}{l}\text { Qtr2 } \\
2007\end{array}$ & $\begin{array}{l}\text { Growth } \\
(\%)\end{array}$ & $\begin{array}{l}\text { Qtr3 } \\
2006\end{array}$ & $\begin{array}{l}\text { Qtr3 } \\
2007\end{array}$ & $\begin{array}{l}\text { Growth } \\
(\%)\end{array}$ \\
\hline \hline Total & 15,490 & 16,358 & $6 \%$ & 14,695 & 15,804 & $8 \%$ \\
Of which: & & & & & & \\
\hline Traditional Media & 12,141 & 12,143 & $0 \%$ & 11,288 & 11,381 & $1 \%$ \\
Share & $78 \%$ & $74 \%$ & & $77 \%$ & $72 \%$ & \\
\hline Online Media & 3,349 & 4,215 & $26 \%$ & 3,407 & 4,423 & $30 \%$ \\
Share & $22 \%$ & $26 \%$ & & $23 \%$ & $28 \%$ & \\
a. Google & 1,421 & 2,030 & $43 \%$ & 1,507 & 2,201 & $46 \%$ \\
Share & $9 \%$ & $12 \%$ & & $10 \%$ & $14 \%$ & \\
b. Yahoo & 1,070 & 1,119 & $5 \%$ & 1,054 & 1,195 & $13 \%$ \\
Share & $7 \%$ & $7 \%$ & & $7 \%$ & $8 \%$ & \\
c. AOL & 449 & 522 & $16 \%$ & 479 & 540 & $13 \%$ \\
Share & $3 \%$ & $3 \%$ & & $3 \%$ & $3 \%$ & \\
d. Microsoft & 409 & 544 & $33 \%$ & 367 & 487 & $33 \%$ \\
Share & $3 \%$ & $3 \%$ & & $2 \%$ & $3 \%$ & \\
\hline \hline
\end{tabular}

Source: Blodget (2008)

Note: Companies include Google, Yahoo, Microsoft, Time Warner, Disney, Viacom, CBS and Clear Chanel, spanning all major advertising sectors: Online, TV, Print, Radio and Outdoor.

across various industries such as distribution networks, toys and clothing manufacture and retailing, allowing them to increase their market power by integrating marketing efforts across different sectors of the media (McChesney, 1999). Many industry observers contend that this unchecked market power has eroded the quality of news, increased partisanship and imposed constraints on the range of issues covered by the Press as well as diversity of opinions expressed. ${ }^{9}$

\subsection{The demand and supply of quality news}

The Pew research center's News interest indices (NII) measure the extent of the American public's interest in various news events. ${ }^{10}$. These indices suggest that

\footnotetext{
9"One cannot expect Disney, for example, to talk too much about sweatshop labor when it is accused of being involved in such things itself." (Shah, 2009)

${ }^{10}$ These indices are based on surveys conducted by the Pew Research Center for the People and the Press. See http://people-press.org/
}

DOI: $10.2202 / 1446-9022.1187$ 
audience interest in various types of news has remained stable since the 1980s, despite the changing composition of news offered by different media platforms. The trends in Figure 1 support this view. While interest in news related to money has trended upwards, there is no other meaningful trend. Importantly, there is no shift in audience tastes towards less serious topics; interest in tabloid news, for instance, has remained low and stable over time. However, there is evidence of sizable discrepancies between the media industry's coverage of news events and consumer preferences.

Figure 1: News Attention Paid to 6 Super Categories of News, By News Era

(\% following "very closely")

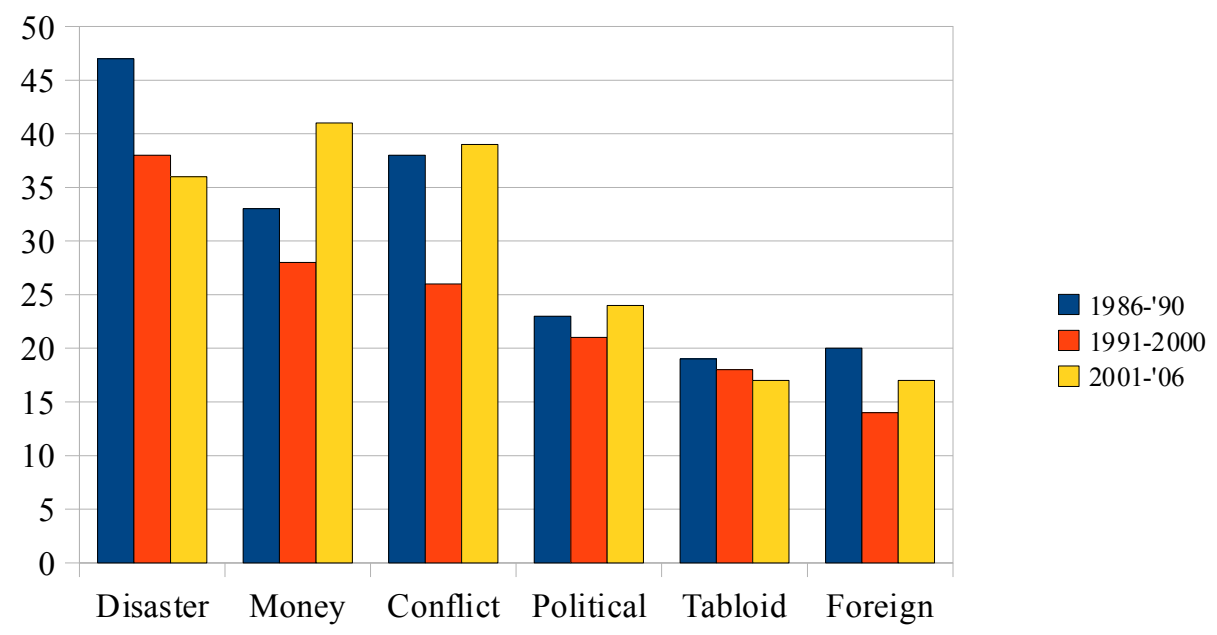

Source: PEW (2007), News Interest Index 1986-2007, Part 2

pewresearch.org/assets/pdf/NewsInterest1986-2007Part2.pdf

Figure 2 highlights the 'news hole' for various events, the gap between the public's interest in a news item and the media's coverage of that event. The figure indicates that what the news media was delivering, did not necessarily accord with audience preferences in terms of coverage. One explanation offered for this mismatch between demand and supply is that the news industry's cost-cutting measures have eroded product quality and driven away their core audiences, those individuals who have traditionally been regular followers of news (Patterson, 2001).

According to the Newspaper Association of America, the number of people employed in the newspaper industry fell by $18 \%$ between 1990 and 2004 . Highquality international news coverage has been a big casualty of these staff cutbacks (Carroll, 2007 and Miller, 2008), as revealed by the following stark statistic: in 
Figure 2: Public Interest vs. Media Coverage, 2007

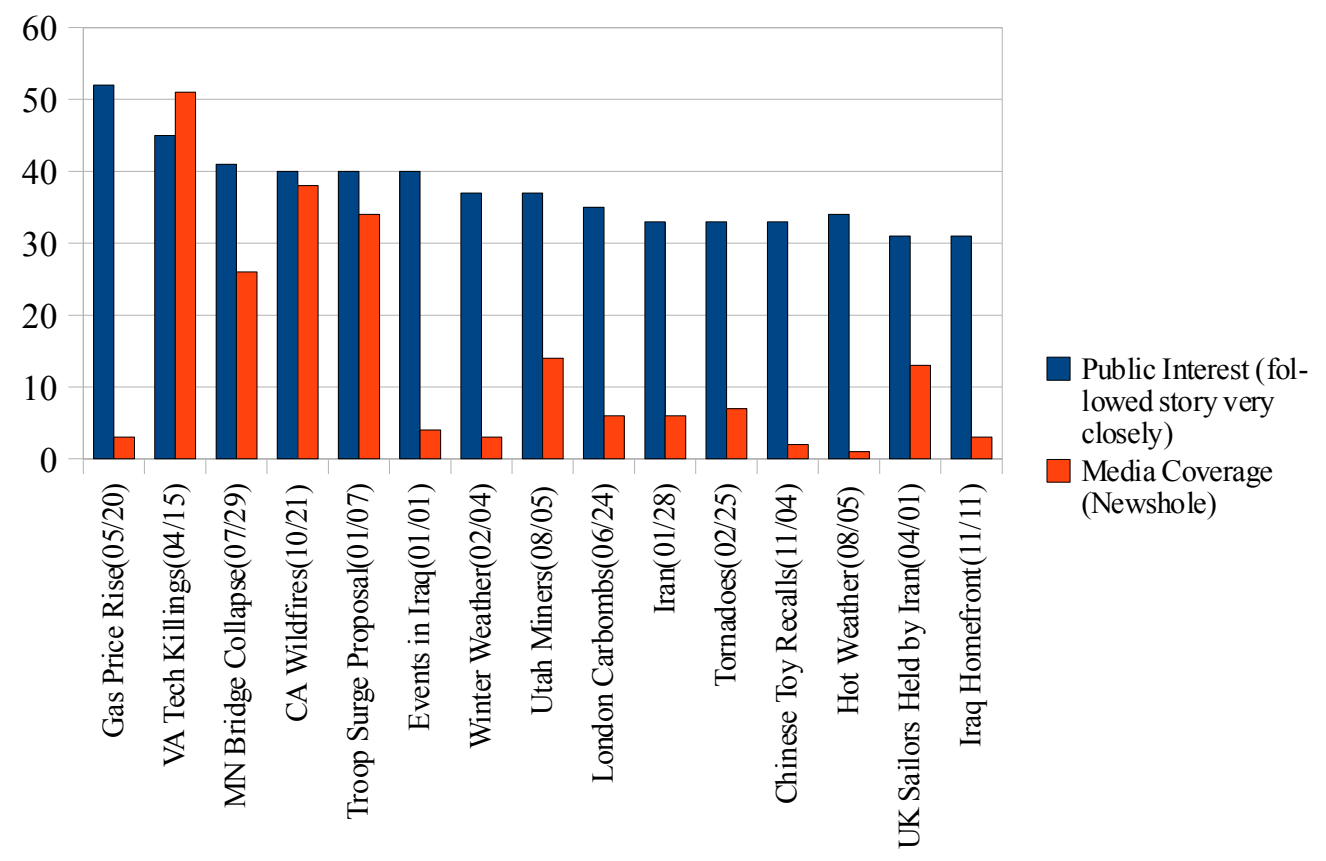

Source: Project for Excellence in Journalism (2007), A Year in the News

2000, two-thirds of the 282 foreign correspondents working abroad for U.S. dailies as either full-timef staff or on exclusive contracts were employed by only four daily newspapers - Wall Street Journal, Washington Post, New York Times and Los Angeles Times. The remainder of over 1,400 dailies had less than a 100 foreign correspondents among them (UNPAN, 2001). Most newspapers now rely on either recycled news from Reuters, the Associated Press (AP) or New York Times wire services, or on mobile journalists who fly into various hot spots to report on the latest crisis. Such reporting invariably lacks cultural perspective and in-depth analysis (Fleeson, 2003). News outlets that have invested in producing high quality news, have enjoyed recognition by their peers as well as high demand.

Table 3 reveals that the four dailies with the largest number of foreign correspondents between themselves won the coveted Pulitzer prize for international reporting in 20 of the 29 years between 1980-2008, signalling high journalistic standards. Since the late 1990s, these dailies have effectively monopolized the Pulitzer prize for this category. Moreover, as Table 4 reports, they have consistently featured among the top ten dailies in the U.S. in terms of circulation. All the above evidence suggests that the demand for high-quality news has remained strong. 
Frijters and Velamuri: Internet and News Quality

Table 3: Winners of Pulitzer Prize for Journalism for International Reporting

\begin{tabular}{|c|c|}
\hline Year & News Daily \\
\hline 1980 & Louisville Courier-Journal \\
\hline 1981 & The Miami Herald \\
\hline 1982 & New York Times \\
\hline 1983 & New York Times; Washington Post \\
\hline 1984 & Wall Street Journal \\
\hline 1985 & Newsday,N.Y. \\
\hline 1986 & San Jose (CA) Mercury News \\
\hline 1987 & Los Angeles Times \\
\hline 1988 & New York Times \\
\hline 1989 & New York Times; Washington Post \\
\hline 1990 & New York Times \\
\hline 1991 & New York Times; Washington Post \\
\hline 1992 & Newsday,N.Y. \\
\hline 1993 & Newsday,N.Y.; New York Times \\
\hline 1994 & Dallas Morning News \\
\hline 1995 & Associated Press \\
\hline 1996 & Christian Science Monitor \\
\hline 1997 & New York Times \\
\hline 1998 & New York Times \\
\hline 1999 & Wall Street Journal \\
\hline 2000 & Village Voice \\
\hline 2001 & Wall Street Journal \\
\hline 2002 & New York Times \\
\hline 2003 & Washington Post \\
\hline 2004 & Washington Post \\
\hline 2005 & Los Angeles Times/Newsday, N.Y. \\
\hline 2006 & New York Times \\
\hline 2007 & Wall Street Journal \\
\hline 2008 & Washington Post \\
\hline
\end{tabular}

Table 5 presents a different and more direct measure of quality - seven readability indices for three newspapers - the New York Times, Christian Science Monitor and the Washington Post - over time. These indices are based on formulae that have been developed to assess the quality of written text, in terms of the ease of 
Review of Network Economics, Vol. 9 [2010], Iss. 2, Art. 2

Table 4: Top 10 U.S. Newspapers, 2006-’08

\begin{tabular}{l|l|l|l}
\hline \hline & 2006 & 2007 & 2008 \\
\hline \hline 1 & USA Today & USA Today & USA Today \\
2 & The Wall Street Journal & The Wall Street Journal & The Wall Street Journal \\
3 & The New York Times & The New York Times & The New York Times \\
4 & Los Angeles Times & Los Angeles Times & Los Angeles Times \\
5 & The New York Post & New York Daily News & New York Daily News \\
6 & New York Daily News & The New York Post & The New York Post \\
7 & The Washington Post & The Washington Post & The Washington Post \\
8 & Chicago Tribune & Chicago Tribune & Chicago Tribune \\
9 & Houston Chronicle & Houston Chronicle & Houston Chronicle \\
10 & Newsday (Long Island) & Arizona Republic- & Arizona Republic- \\
& & Phoenix & Phoenix \\
\hline \hline
\end{tabular}

Source: Audit Bureau of Circulations;

Note: Ranked by weekday averages for 6 months ending 30th

September

comprehension for readers. Each uses a different formula for predicting readability but essentially, they all look at the lengths of words and sentences. This is obviously not a critique-free means of measuring quality but does measure the degree to which the text taxes the reader. ${ }^{11}$ To assess the readability of various newspaper articles, we selected one article from a March issue in every decade from the online archives of the respective newspaper websites. To the extent possible, we restricted our attention to editorial articles, since these are most reflective of the writing style followed by the newspapers.

\footnotetext{
${ }^{11}$ Some, like the Flesch-Kincaid measure and the Flesch reading ease formula, are based on the number of syllables per word and the average sentence length, while others like the ARI and the Coleman-Liau, are based on the number of characters per word and sentence length. See http://www.readability.info/info.shtml for the formulae used in computing these indices. With the exception of the Flesch index, all other measures report the output in terms of a U.S. grade-school level required to comprehend the text.
} 
Frijters and Velamuri: Internet and News Quality

Table 5: 'Readibility' Scores for Select Newspaper Articles, Various Years

\begin{tabular}{|l|l|l|l|l|l|l|l|l|l|l|l|l|}
\hline \hline & \multicolumn{3}{|c}{ New York Times } & \multicolumn{4}{c}{ Christian Science Monitor } & \multicolumn{3}{c}{ Washington Post } \\
\hline \hline & 1981 & 1990 & 2000 & 2007 & 1980 & 1990 & 2000 & 20071980 & 1990 & 2000 & 2007 \\
\cline { 2 - 11 } Flesch-Kincaid & 9.4 & 11.0 & 13.7 & 13.0 & 10.3 & 10.9 & 10.8 & 10.9 & 12.4 & 11.9 & 11.2 & 13.5 \\
ARI & 10.7 & 12.2 & 15.5 & 14.8 & 11.3 & 12.4 & 11.6 & 12.1 & 14.4 & 13.2 & 12.9 & 16.1 \\
Coleman-Liau & 12.4 & 14.6 & 12.7 & 10.5 & 12.6 & 14.5 & 11.8 & 12.2 & 15.0 & 11.9 & 14.8 & 14.8 \\
Flesch Index & 62.2 & 49.2 & 47.3 & 56.0 & 56.8 & 51.2 & 57.1 & 56.8 & 45.9 & 54.5 & 49.9 & 44.7 \\
Fog Index & 12.2 & 14.1 & 17.4 & 16.0 & 12.4 & 13.5 & 13.9 & 14.4 & 16.5 & 15.7 & 14.4 & 17.3 \\
Lix & 8 & 9 & 10 & 9 & 8 & 9 & 8 & 8 & 11 & 9 & 9 & 11 \\
SMOG-Grading & 11.0 & 12.6 & 14.3 & 12.3 & 12.0 & 12.1 & 12.2 & 12.6 & 14.2 & 13.3 & 12.8 & 14.6 \\
\hline
\end{tabular}

Note: Indices computed using online tool http://www.readability.info/info.shtml. Indices computed for 1 article selected from a March issue in each year, sourced from online archives of newspaper websites. Flesch-Kincaid Grade - converts the Reading Ease Score to a U.S. grade-school level needed to comprehend the text. ARI - automated readability index. Its output is an approximate representation of the U.S. grade level needed to comprehend the text. Coleman-Liau - Its output is an approximate representation of the U.S. grade level needed to comprehend the text. Flesh index - value is usually between 0 (hard) and 100 (easy); standard English documents averages approximately 60 to 70. Fog index - the value is a school grade. The 'ideal' level is 7 or 8 . A level above 12 indicates the writing sample is too hard for most people to read. Lix - Its output is an approximate representation of the U.S. grade level needed to comprehend the text. SMOG-Grading for English texts reports a school grade required to comprehend the text. 
The different measures of readability in Table 5 are generally consistent. They suggest that while the Washington Post appears to adopt a more complex writing style relative to the other two dailies, the trends in each of the dailies have remained quite stable over time; there is no evidence of any 'dumbing down' in the writing style. Clearly, these measures are quite limited; they do not capture any deeper characteristics of writing such as coherence of argument or quality of analysis. Nevertheless, they are objective measures of the surface readability of representative articles. The indices in Table 5 suggest that in terms of various readability metrics, these dailies have maintained their standards over time.

Trends in circulation of news magazines also suggest that audiences have gravitated towards outlets that specialize in particular types of news or analysis. The Economist magazine, for instance, specializes in in-depth foreign economic news from all corners of the globe. At a time when news magazines like Time and Newsweek were moving away from hard news ${ }^{12}$, readership of the Economist magazine increased dramatically. Since 1993, the magazine has more than doubled its readership in the U.S., which now accounts for over half of its world-wide sales (Langfitt, 2006). This dramatic increase in circulation is further evidence that there is a sizeable audience for high-quality news in the U.S. Other specialized magazines such as the New Yorker and the Week have all seen their circulation rise substantially during the last 20 years. ${ }^{13}$ Figure 3 attests to this rising trend, while Figure 4 traces the gradual erosion in readership among the magazines that were traditionally considered the 'big three' - Newsweek, Time and U.S. News. All three face circulation numbers that are below their respective 1988 levels.

A different measure of news quality is the composition of hard versus soft news on offer. ${ }^{14}$ Several high-profile news organizations have adopted an editorial direction towards a more tabloid style in the last 10 years, as a means of lowering their costs. ${ }^{15}$ Patterson (2001) documents a discernible shift away from traditional, hard news towards softer content among different media platforms between 1980 and 1999. According to his analysis, news stories with moderate to high levels of sensationalism have increased from $25 \%$ to $40 \%$, news stories with a human interest

\footnotetext{
${ }^{12}$ See Nisbet, 2001

${ }^{13}$ The National Geographic magazine, specializing in geography, culture and environmental issues, has similarly retained its high standards for quality for well over a century and is currently published in over 31 languages, with a combined circulation of over 9 million annually (http://www.answers.com/topic/national-geographic-society)

${ }^{14}$ Patterson (2001) defines 'hard' news as information that is important to citizens' ability to understand and respond to the world of public affairs. Examples include breaking events involving top leaders, major issues, or significant disruptions in the routines of daily life, such as an earthquake or airline disaster. 'Soft' news or tabloid news, on the other hand, is news unrelated to public affairs or policy, and is more sensational and/or more personality or celebrity-oriented.

${ }^{15}$ See Miller (2008), http://www.pri.org/global-news.html
} 
Frijters and Velamuri: Internet and News Quality

Figure 3: Circulation of Non-Traditional Magazines in the U.S 1988-2004

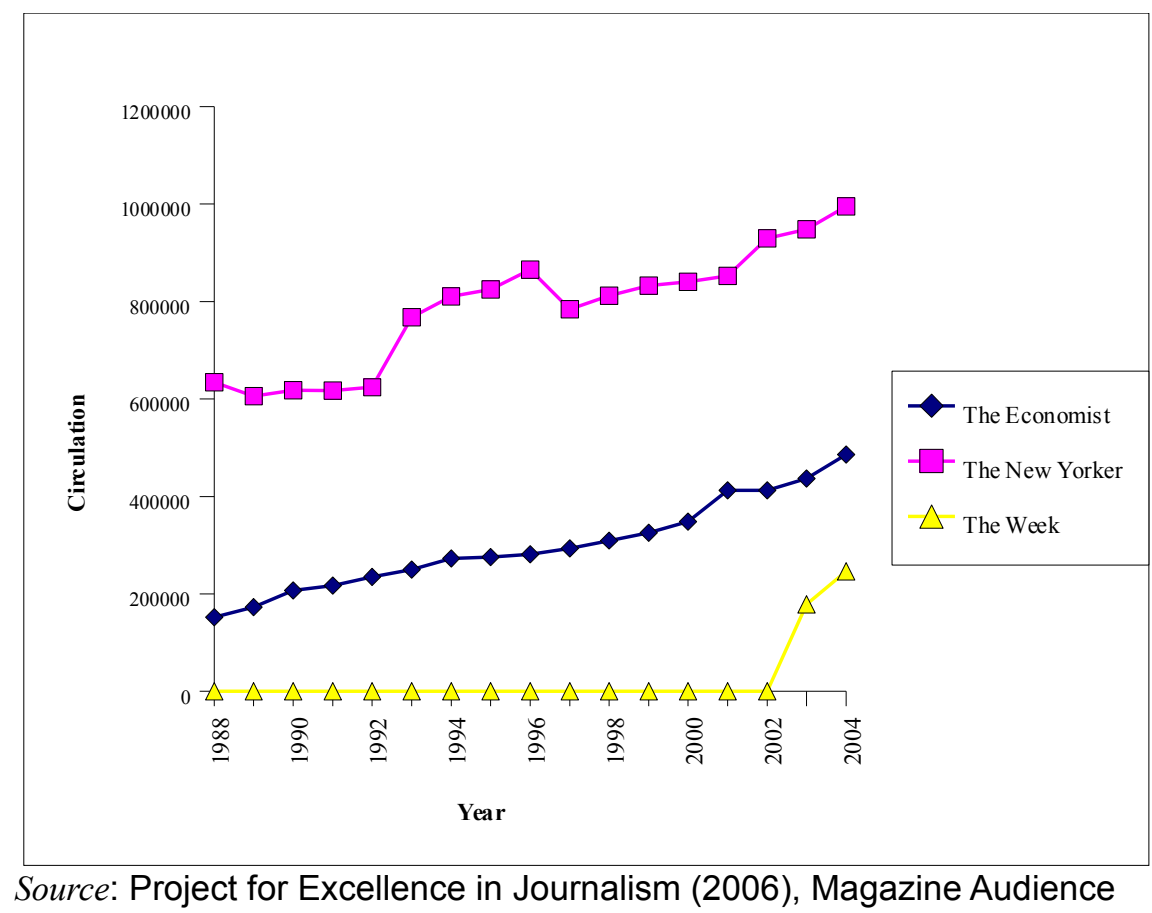

element have increased from $11 \%$ to $26 \%$, and news stories relating to crime and disasters have increased from $8 \%$ to over $13 \%$ during this period. However, as mentioned earlier (see Figure 1), data from opinion polls indicates no evidence of a concomitant shift in the public's preferences towards soft news.

These trends suggest that it is not so much that high-quality news is no longer produced or disseminated, but rather that it has become a truly specialized commodity. With the mainstream media implementing staff cut-backs, eschewing in-house reporting and relying more and more on syndicated news, consumers interested in original, high-quality reporting have gravitated towards specialist providers of such news. As a result, we are now witnessing a more segmented market for news.

\subsection{The direct effects of the internet}

The emergence of the World Wide Web in the mid-1990s signalled a new era in publishing and redefined the traditional newspaper audience. In 2008, 55\% of all 
Figure 4: Circulation Among 'Big Three' News Magazines in the U.S. 1988-2004

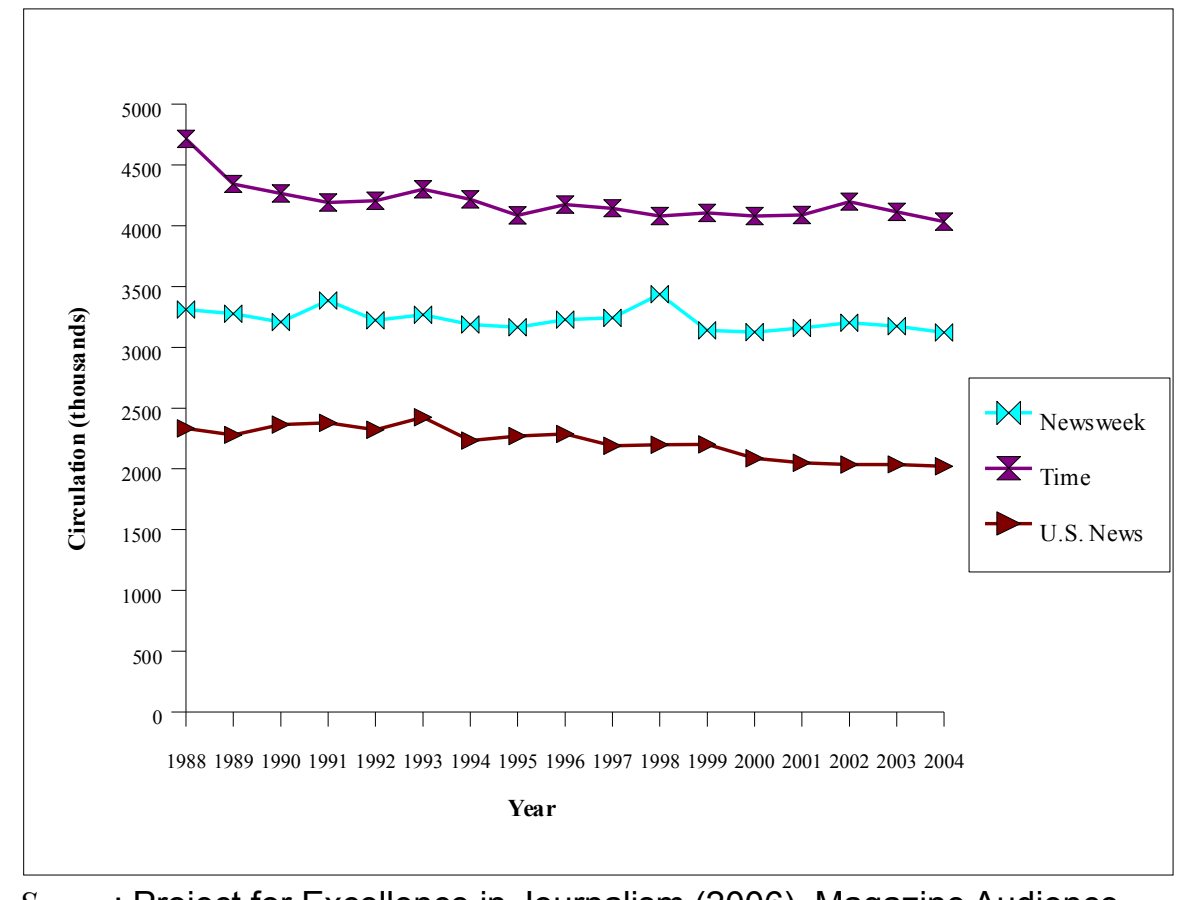

Source: Project for Excellence in Journalism (2006), Magazine Audience

adult Americans had a high-speed internet connection at home (Pew, 2008). As a consequence, the internet has drawn news audiences away from mainstream media sources. Gentzkow (2007) provides some evidence in support of this; he examined whether the advent of online news has complemented or crowded out print newspapers. Using microdata from the Washington DC market and carefully controlling for unobserved consumer heterogeneity, he found that on average, online news reduces readership of print news by 27,000 readers per day and costs firms US\$ 5.5 million per year in lost print profits. ${ }^{16}$

A large section of the print and visual media has responded by embracing the Web, taking its content online and integrating audio and video features on the internet sites. Previously, newspapers reserved their best journalists for the print versions. Now they are contributing to their online versions, as the second quote in the introduction testified to. Table 6 records the steep increase in visitor traffic to online newspaper websites since 2006, and Table 7 presents revenues of newspapers from their online operations in 2006, classified by circulation.

${ }^{16}$ Filistrucchi (2005) provides similar evidence for Italy. 
Frijters and Velamuri: Internet and News Quality

Table 6: Total Web Audience for Newspaper Websites, 2006-'09

\begin{tabular}{|c|c|c|c|c|c|c|}
\hline & $\begin{array}{l}\text { Unique } \\
\text { Audience } \\
\text { (millions) }\end{array}$ & $\begin{array}{l}\text { Active } \\
\text { Reach \% }\end{array}$ & $\begin{array}{l}\text { Web Page } \\
\text { Views } \\
\text { (millions) }\end{array}$ & $\begin{array}{l}\text { Pages/ } \\
\text { Person }\end{array}$ & $\begin{array}{l}\text { Time/Person } \\
\text { (hh:mm:ss) }\end{array}$ & $\begin{array}{l}\text { Visits/ } \\
\text { Person }\end{array}$ \\
\hline Jan-09 & 74.81 & 44.34 & 3725.77 & 49.80 & 00: 45: 58 & 8.48 \\
\hline Dec-08 & 66.67 & 40.13 & 2959.56 & 44.39 & $00: 42: 18$ & 8.46 \\
\hline Nov-08 & 69.05 & 40.77 & 3276.17 & 47.45 & $00: 45: 02$ & 8.69 \\
\hline Oct-08 & 68.97 & 42.17 & 3537.25 & 51.29 & 00: 49: 08 & 9.27 \\
\hline Sep-08 & 67.7 & 41.53 & 3686.18 & 54.45 & 00: 49: 20 & 9.20 \\
\hline Aug-08 & 69.31 & 41.52 & 3421.61 & 49.36 & 00: 43: 18 & 8.52 \\
\hline Jul-08 & 67.95 & 41.21 & 3410.22 & 50.19 & 00: $44: 49$ & 8.48 \\
\hline Jun-08 & 65.42 & 39.89 & 3137.65 & 47.96 & $00: 40: 23$ & 8.17 \\
\hline May-08 & 69.41 & 41.70 & 3040.57 & 43.81 & 00: 39: 51 & 7.91 \\
\hline Apr-08 & 64.34 & 39.11 & 2851.47 & 44.32 & $00: 41: 13$ & 8.15 \\
\hline Mar-08 & 65.69 & 39.90 & 3111.86 & 47.38 & $00: 43: 37$ & 8.30 \\
\hline Feb-08 & 66.55 & 41.00 & 3064.61 & 46.05 & 00: 43: 09 & 8.07 \\
\hline Jan-08 & 66.88 & 41.32 & 3228.54 & 48.27 & $00: 45: 49$ & 8.48 \\
\hline Dec-07 & 63.05 & 38.20 & 2888.76 & 45.82 & $00: 41: 57$ & 7.83 \\
\hline Nov-07 & 62.28 & 38.88 & 2939.5 & 47.20 & $00: 42: 20$ & 7.94 \\
\hline Oct-07 & 63.21 & 39.77 & 3240.78 & 51.27 & 00: 46: 44 & 8.59 \\
\hline Sep-07 & 58.16 & 36.96 & 2836.33 & 48.77 & $00: 43: 44$ & 8.15 \\
\hline Aug-07 & 59.28 & 37.42 & 2828.61 & 47.72 & $00: 41: 52$ & 8.22 \\
\hline Jul-07 & 59.64 & 37.05 & 2735.02 & 45.86 & 00: 40: 07 & 8.00 \\
\hline Jun-07 & 58.62 & 36.74 & 2507.51 & 42.77 & 00: 39: 55 & 7.55 \\
\hline May-07 & 60.25 & 37.78 & 2726.83 & 45.26 & 00: 40: 16 & 7.91 \\
\hline Apr-07 & 58.68 & 37.40 & 2761.3 & 47.06 & 00: 42: 01 & 8.01 \\
\hline Mar-07 & 59.6 & 37.74 & 2987.84 & 50.13 & 00: 44: 09 & 8.56 \\
\hline Feb-07 & 58.76 & 37.47 & 2827.94 & 48.12 & $00: 43: 33$ & 7.94 \\
\hline Jan-07 & 58.9 & 37.56 & 3149.86 & 53.48 & 00: 49: 11 & 8.67 \\
\hline Dec-06 & 56.01 & 34.68 & 2688.69 & 48.00 & $00: 42: 55$ & 7.80 \\
\hline Nov-06 & 58.13 & 36.33 & 2792.08 & 48.03 & 00: 41: 59 & 7.93 \\
\hline Oct-06 & 58.72 & 37.18 & 2975.45 & 50.67 & 00: 44: 04 & 8.16 \\
\hline Sep-06 & 58.19 & 37.03 & 2781.41 & 47.80 & 00: 42: 01 & 7.94 \\
\hline Aug-06 & 57.96 & 37.23 & 2779.65 & 47.96 & 00: 43: 17 & 8.21 \\
\hline Jul-06 & 54.65 & 35.29 & 2550.84 & 46.68 & 00: 39: 19 & 7.92 \\
\hline Jun-06 & 54.5 & 34.99 & 2532.26 & 46.46 & 00: 39: 10 & 8.01 \\
\hline
\end{tabular}

Source: Nielsen Online, MegaPanel Data

http://www.naa.org/TrendsandNumbers/Newspaper-Websites.aspx 
Table 7: Newspaper Websites - Unique Visitors Vs. Online Revenue in 2006

\begin{tabular}{|l|l|l|l|l|l|l}
\hline \# Unique & $\begin{array}{l}<=\$ 0.5 \\
\text { Visitors }\end{array}$ & $\begin{array}{l}\$ 0.5 \mathrm{~m}- \\
1 \mathrm{~m}\end{array}$ & $\begin{array}{l}\$ 1 \mathrm{~m}- \\
5 \mathrm{~m}\end{array}$ & $\begin{array}{l}\$ 5 \mathrm{~m}- \\
10 \mathrm{~m}\end{array}$ & $\begin{array}{l}\$ 10 \mathrm{~m}- \\
15 \mathrm{~m}\end{array}$ & $>=\$ 15 \mathrm{~m}$ \\
\hline \hline$<=25000$ & $100 \%$ & $0 \%$ & $0 \%$ & $0 \%$ & $0 \%$ & $0 \%$ \\
$25,001-50,000$ & $100 \%$ & $0 \%$ & $0 \%$ & $0 \%$ & $0 \%$ & $0 \%$ \\
$50,001-100,000$ & $71 \%$ & $21 \%$ & $7 \%$ & $0 \%$ & $0 \%$ & $0 \%$ \\
$100,001-250,000$ & $43 \%$ & $23 \%$ & $30 \%$ & $0 \%$ & $0 \%$ & $0 \%$ \\
$250,001-500,000$ & $17 \%$ & $13 \%$ & $52 \%$ & $17 \%$ & $0 \%$ & $0 \%$ \\
$500,001-1,00,000$ & $17 \%$ & $6 \%$ & $28 \%$ & $50 \%$ & $0 \%$ & $0 \%$ \\
$>1,000,000$ & $4 \%$ & $0 \%$ & $0 \%$ & $12 \%$ & $20 \%$ & $64 \%$ \\
\hline \hline
\end{tabular}

Source: Lawton (2007)

The circulation numbers in Table 6 indicate a substantial growth in online news audience and the cross-tabulations in Table 7 suggest that advertising-based internet news-provision has been a viable business model. Recent examples of news outlets switching to online news include the century-old Christian Science Monitor which decided to reduce its costs by abandoning its daily print edition and moving to an exclusively online edition. Significantly, the paper announced that such a move would allow it to keep its eight foreign bureaus open. In March 2009, the Seattle-based daily Post-Intelligencer, founded in 1863 and currently owned by the Hearst Corporation, also announced its decision to abandon its print edition to move online, in a bid to bring down its operating losses. Thus, some newspapers are converting from hard-copies to internet-based outlets.

Another impact of broadband expansion has been on the state of journalism itself. Facilitated by the development of interactive tools like Live Journal and blogger.com, it has created a community of bloggers who perform three functions: (i) express opinions on various topics and invite comment; some newspapers are bringing popular blogs into their domain and generating content through these channels. For example, the online edition of the New York Times hosts the 'Freakonomics' blog. This would seem a clear move to retain the advertising revenue generated by providing a bundle of news; (ii) conflate information from various original sources including newspapers; Web-based news aggregators like Google news and My Yahoo facilitate this activity, as do user-driven news sites like Reddit and Digg, by posting those news items that online viewers find most interesting; and (iii) bring key information to public light. The third function has made blogging a powerful medium for the dissemination of news and created a corps of self-appointed 'citizen 
journalists'. ${ }^{17}$ Supporters of this new form of participatory journalism assert that blogs have become "a powerful antidote to media consolidation." (Drum, 2007). Hume (1995) has asserted that the internet could be a powerful disciplinary device for journalists: "As consumers start experimenting in cyberspace, journalists need to address more urgently not the delivery format but the quality of their core product: reliable and useful information on which citizens can act." (p.153)

\subsection{Stylized facts}

The review above generates the following stylized facts we wish to provide a simple model for:

1. The news industry is dominated by local and global monopolies on particular markets.

2. While the demand for quality news appears stable, the provision has become more specialized: the quality of the top brands does not appear compromised but mainstream news provision has become increasingly de-coupled from quality news.

3. The business model of the internet is similar to that of early television: costs are recouped via the traffic attracted to a bundle of news that generates advertising opportunities.

In the following section, we develop a simple model to capture these stylized facts.

\section{Model}

We consider the market for high-quality news where we see high-quality news as a combination of primary news provision (generated at cost $C_{0}$ ), and checking the statements made by primary news providers (at $\operatorname{cost} c$ ). The checking of primary news is in effect an intermediary role which requires looking up references and follow-up, which is a cost that is intimately related to the internet in that the cheaper cost of information dissemination on the internet directly reduces the cost of checking facts. In the remainder, the effect of the increasing presence of the internet will always work via a reduction in the search costs captured by $c$. The generation

\footnotetext{
${ }^{17} \mathrm{~A}$ number of scandals that caused prominent public figures to resign their official positions for example, Trent Lott as the U.S. Senate majority leader in 2002, and Dan Rather as a television journalist on CBS in 2005 - were initiated by blogs.
} 
of original news content requires travel, information gathering, interviewing news sources, synthesizing information etc, and carries a cost taken to be invariant to the internet. ${ }^{18}$. The two activities go into a composite commodity called high-quality news that carries unit costs of $C_{0}+c$ per period. We do not distinguish between the provision of news via a physical medium and the internet, implying that our model includes internet news providers. We will first only consider business models where news has to pay for itself, and then later include the role of advertising.

On the buyer side of the market, there is a continuum of consumers of measure $M$ whose willingness to pay for high-quality news is uniformly distributed between 0 and $\gamma \cdot{ }^{19}$ We interpret $M$ as the size of the community interested in the specific high-quality news offered by a provider. We can think of a small $M$ as the market for high-quality news on local politics and a high $M$ as the market for high-quality news on national or international politics. This means that the same individual can be in several markets at the same time. We summarize this interpretation by presuming that there is a continuum of markets for different types of high-quality news, each associated with a particular $M$. We denote the cdf of this distribution as $Q(M)$ whose pdf $q(M)$ we presume exists and is continuous and positive on $\infty>M>0$.

We assume that buyers are able to observe the costs made by the producers of high-quality news and thus know who is providing high-quality news and who is not. Whilst this assumption is probably invalid in the short-run because it may take agents some time to find out how much effort a news provider actually puts into providing high-quality news, long-run reputation is linked to the real actions of the news providers. In this sense, our model should be seen as a long-run model that abstracts from the short-run possibility that reputations are imperfect.

As to market interaction, we assume classic Bertrand competition with a first-mover who can produce news after which a competitor would have to decide whether or not to enter. Then, there will only be one producer because any second mover knows the ensuing price war would lead to a loss, since high-quality news only needs to be produced once after which it can be sold on for nothing. Hence the first-mover will have a natural monopoly in its production. This assumption implies we really only analyze whether or not a market is active. The profit function for an active monopolist on market $M$ as a function of its price reads:

$$
\pi(p, M)=M p\left(\frac{\gamma-p}{\gamma}\right)-C_{0}-c
$$

\footnotetext{
${ }^{18}$ What is important is not that $C_{0}$ is completely independent of the cost of the internet but that it goes down less than proportionally with $c$.

${ }^{19}$ In later extensions we will interpret this distribution in willingness to pay as the opportunity cost of searching for a free copy.
}

DOI: $10.2202 / 1446-9022.1187$ 
where $\frac{\gamma-p}{\gamma}$ is the proportion of potential buyers willing to pay $p$ for the high-quality news. This function has a maximum at $p=\frac{\gamma}{2}$ and profits are non-negative as long as

$$
M>4 \frac{C_{0}+c}{\gamma}
$$

The proportion of markets to which high-quality news is provided is denoted as $N$ and equals $1-Q\left(4 \frac{C_{0}+c}{\gamma}\right)$. This means that a decrease in the cost of checking information $(c)$ would lead to an increase in the proportion of markets for which high-quality news is provided by an amount

$$
\frac{d N}{d(-c)}=\frac{4}{\gamma} q\left(4 \frac{C_{0}+c}{\gamma}\right)
$$

which is strictly positive. This is the positive effect of the internet on the provision of high-quality news.

This basic case also gives a natural framework in which to think about the specialisation and de-bundling that has taken place in the market for news with the advent of the internet. We can see the introduction of the internet as a one-off merging of many geographically separated markets. This effectively means that all the geographically local monopolists, who would have provided both local and non-local news, suddenly had to compete with international competitors for nonlocal news, which would quickly have lead to a single global monopolist on any particular non-local news area. The local monopolists would remain as the global monopolist' of local news (including local human interest stories, local politics, local sports, etc.). The observed de-bundling of news is then the visible impact of the previous local monopolist being undercut by global specialised competitors on non-local news, leading local news providers to no longer supply the local market for non-local news.

\subsection{The effect of adding blogging and news aggregation}

One of the activities of bloggers and news aggregators is to recycle the information generated by news providers. They comment on and effectively re-publish the articles and information in question. This means that to access bloggers and aggregators on particular topics is getting the quality signal of the high-quality news provider for free. However, there is a cost associated with finding the right site, just as before the advent of the internet there was a cost associated with getting a free copy of a high-quality news publication. Before the advent of the internet, one could go to news cafés or peek at the paper of the person sitting alongside on 
the train, thus avoiding having to pay for the high-quality news. With the internet, blogging and aggregators allows the same kind of access but at a lower price.

Formalizing this argument, we presume that individuals are distributed uniformly on a $[0, H]$ scale where $h \in[0, H]$ denotes the effective number of searches an individual needs to make in order to obtain a piece of high-quality news for free. One can interpret this distribution as the distribution of the opportunity cost of individuals, or alternatively as the shame they experience when searching for a free copy of something that is actually priced. The actual cost that someone then incurs is the number of searches needed to find a free copy times the marginal cost per unit of search, i.e. $h c$ where $c$ is again a measure of the search costs that get reduced via the internet. We can interpret this heterogeneity in search costs $h c$ as the source of an individual's willingness to pay while in terms of enjoyment of high-quality news, all consumers gain the same level of utility $\gamma$. The proportion of consumers on market $M$ who will buy a piece of high-quality news at price $p$ then becomes $(\min (\gamma, H c)-p) / H c$. Ignoring the trivially complicating possibility that $\gamma<H c$, this means we take the profit problem for the firm with blogging in market $M$ to be

$$
\pi=M p\left(\frac{H c-p}{H c}\right)-C_{0}-c
$$

which is maximized at $p=\frac{H c}{2}$ and $\pi^{*}=c\left(M \frac{H}{4}-1\right)-C_{0}$. The effect of a reduction in the marginal cost of searching for information $(c)$ now equals

$$
\frac{d \pi^{*}}{d(-c)}=-M \frac{H}{4}+1
$$

where the second term shows the positive effect of reduced cost, but the first term shows the effect of loss of market size due to the increase in customers turning to bloggers and aggregators rather than buying high-quality news. Note that it has to be the case that $M \frac{H}{4}>1$ for all markets with positive profits, implying that $\frac{d \pi^{*}}{d(-c)}<$ 0 . Profits are positive in those markets where

$$
M>4 \frac{1+\frac{C_{0}}{c}}{H}
$$

which means that a decrease in cost now has a different effect on the number of markets provided with a high-quality news service:

$$
\frac{d N}{d(-c)}=\frac{-4 C_{0}}{c^{2} H} q\left(4 \frac{1+\frac{C_{0}}{c}}{H}\right)
$$

This implies that the number of active markets will decrease with the advent of the combination of internet and blogging under a business model in which news has to pay for itself. 
As to welfare implications, we note that the consumer surplus of highquality news of price 0 equals $M \gamma$. Hence, in the absence of concerns about conflict of interest - for instance, that elected officials may be controlling a media that is supposed to be the public's watchdog monitoring the activities of those very same elected officials - there is a welfare argument that all markets with $M \gamma>C_{0}+c$ should have a state-provider. If we interpret the market for high-quality news as the market for news on the misdeeds of the government, then there is no valid case for state-provision of that good. There might still be a case for provision by independent organizations like non-profits.

\subsection{Further long-term implications: market separation}

We conceptualize high-quality news provision as effectively offering two distinct services. One is the intermediary service of checking the factual validity of statements, which comes at a marginal cost proportional to the search cost of the internet. We are here thinking of news providers taking the stories of the news agencies (TASS/Reuters) and doing no more than a quick google-check on consistency of numbers brought out by press-statements, with data from other online sources such as statistical agencies or online encyclopedias. The second is generating new information at a fixed-price unrelated to the cost of the internet. This includes, among other things, interviewing various human sources, on-site inspections, and other news-making activities that cannot be conducted from behind a computer. While traditional high-quality media can be seen as a combination of both, one can envisage these two activities being separated into what we denote as 'News-making' and 'News-checking'. We can introduce these two activities by simply having markets for single units of local 'new news' with a cdf of $Q^{*}(M)$ and markets for single units of 'checked-news' with a cdf of $Q^{+}(M)$. In order to avoid introducing more superfluous notation, we keep the willingness-to-pay parameters the same as above.

The proportion of the markets for news-making that is active, $N^{*}$, will decrease with the advent of blogging. Following the same chain of reasoning as above and assuming for simplicity that we can split the markets for a unit, the change in the market for news-making due to the reduction in search costs for high-quality news as a result of blogging on the internet will be

$$
\frac{d N^{*}}{d(-c)}=\frac{-4 C_{0}}{c^{2} H} q^{*}\left(4 \frac{\frac{C_{0}}{c}}{H}\right)
$$

which is strictly negative.

The markets for news-checking will see a different effect: following the same chain of reasoning as above, the profits in active markets will be: 


$$
\begin{aligned}
\pi & =M p\left(\frac{H c-p}{H c}\right)-c \\
& =c\left(M \frac{H}{4}-1\right)
\end{aligned}
$$

which goes up linearly in $c$. The proportion of active markets is given by

$$
N^{+}=1-Q^{+}\left(\frac{4}{H}\right)
$$

which is independent of $c$, implying that there is no change in the amount of newschecking that goes on with the advent of blogging: the reduction in the cost of checking facts is at the same rate as the reduction in the cost of finding 'checkednews' on a blog. Hence all that blogging does is to reduce the profits made by a 'news-checker', not the level of activity. This outcome would change in obvious ways if the costs-of news checking are not proportional to the search costs of blogconsumers and blog-producers. If there is a fixed cost of news-checking that is relatively higher than the fixed cost of blog-consumption or production, then newschecking starts to suffer from the same problem as news making in that its fixed costs will not be recouped as search costs go to zero.

\subsection{The role of advertising}

We argued in the empirical section that a large proportion of the revenue for news providers, both on-line and off-line, is not from the direct sale of vetted news but from advertising. Advertisers want to reach many people and as such, it is the volume of sales that is a prime determinant of the price of advertising space. A constraint newspapers face in compensating their consumers for advertisements by lowering their price is that they cannot charge negative prices, effectively because they cannot force their readers to read the newspapers they have been bribed to receive.

We incorporate the basic approach of Gaszewicz et al. (2006) regarding advertising to our model. They assume that consumers dislike advertising, while the marginal gain to advertisers decreases with additional advertisements. We bring these assumptions into our model by presuming that newspapers offer a priceadvertisement package $\{p, a\}$ and that consumers have a marginal distaste for each unit of advertising equal to $f$. This means that a consumer will prefer to search for advertisement-free online news if $h<p+f a$.

The marginal value of an additional ad to advertisers is taken to be linear in the number of readers, i.e. the marginal value to advertisers is 
Frijters and Velamuri: Internet and News Quality

$$
g * M \int_{0}^{H c} \frac{I[h<p+f a]}{H c} d h
$$

where $g>0$. Here,

$$
\int_{0}^{H c} \frac{I[h<p+f a]}{H c} d h=\frac{H c-p-f a}{H c}
$$

denotes the proportion of potential readers buying their hard news from the originator.

Since the news provider can extract all the rents from the advertisers by charging them the price $g M \frac{H c-p-f a}{H c}$ per unit of avertising $a$, we can write the profit function in the market of news-making as:

$$
\pi=M[p+a g] \frac{H c-p-f a}{H c}-C_{0}
$$

This implies that in equilibrium either $a$ or $p$ will equal zero. If the marginal value of advertising to the advertiser is higher than the marginal distaste to the consumer $(g>f)$, then $p=0$ and $a=\frac{H c}{2 f}$. If instead $g<f$ then $a=0$ and $p=\frac{H c}{2}$. In the case that advertising effectively is unprofitable $(g>f)$, we are back in the case above, so we need only here look at the case with advertising. Profits are then positive as long as

$$
M>\frac{4 f C_{0}}{g H c}
$$

which implies that $M$ monotonically decreases with $c$ and hence the number of active markets goes up as the costs of search goes up. Conversely at low values of $c$, only those markets whose costs can be recouped via advertising by a sufficient number of potentially interested customers are active. This result has the intuitive implication that with a 'perfect' internet, on which the search costs become arbitrarily close to zero, there are less active markets for news-making than with an imperfect internet with higher search costs. If the importance of advertising increases (meaning that $\frac{g}{f}$ increases) then the number of active markets increases.

In the market for news-checking we get a slightly different result. Profits are positive as long as

$$
M>\frac{4 f}{g H}
$$

which is hence independent of $\mathrm{c}$ under the crucial assumption that both the costs of news checking and the cost of avoiding advertising decrease at the same rate when advertising is the only source of income. We thus find that news-checking 
is unaffected from further reductions of search costs via the internet, whilst newsmaking suffers.

Any additional rent-skimming on the revenue of avertising, such as via news aggregators and search engines, can be seen from the viewpoint of the news provider as a reduction in the marginal price they can charge the advertiser and thus as a decrease in $g$.

\subsection{Endogenous quality}

So far, we have conceptualised quality as being innate to a particular market and merely wondered which markets would be active. This leaves no room for markets that continue being served but where quality levels have gone down; many argue this has happened to the mass market. In this final sub-section we try to capture the main effect of the internet on quality by taking an alternative modelling approach to the one above. For the purposes of this section hence, we consider a single market, including the possibility of advertising as above, where the cost to a news maker of generating a quality $z$ equals $C(z)$ which is increasing and convex in $z$ with $C(0)=C_{0}$.

We envisage the role of the internet now as providing free-entry to a competitor (entrant) who offers a related product to the monopolist news-maker. In order to allow for a role of the internet that is different from directly copying the product of a news-maker (which is similar to the situation above, the only question being how difficult it is for individuals to find the competitor), we now envisage the entrant as someone who is able to only copy the product of the news maker imperfectly, i.e. the quality offered by the entrant equals $\tilde{z}=z * b$ with $0<b<1$. The total costs of this new entrant equals $c$ which we again interpret as a search cost. The advent of the internet is hence, as before, conceptualised as a decrease in $c$. Consumers are now characterised by both a fixed marginal distaste of advertisements while having a uniformly distributed marginal taste for quality on $[0, \gamma]$. We abstract from any costs consumers might incur in order to find the online competitor and merely look at the quality motive consumers might have in order to remain with a news maker.

The choices of the news maker are the level of quality $z$, the price charged $p$, and the amount of advertising $a_{0}$. The choices of the entrant are whether to exist, and how much advertising $a_{1}$ to have. The news maker is the first mover and we are looking for a subgame perfect equilibrium. The number of consumers that will buy from a newsmaker equal

$$
\frac{1}{\gamma} \int_{1}^{\gamma} I\left[q z-p-f a_{0}>\max \left\{0, q z b-f a_{1}\right\}\right] d q
$$


Frijters and Velamuri: Internet and News Quality

while the number of consumers going to the internet entrant will equal

$$
\frac{1}{\gamma} \int_{1}^{\gamma} I\left[q z b-f a_{1}>\max \left\{0, q z-p-f a_{0}\right\}\right] d q
$$

The profit function of the news maker reads

$$
\pi_{0}=\frac{p+g a_{0}}{\gamma} \int_{1}^{\gamma} I\left[q z-p-f a_{0}>\max \left\{0, q z b-f a_{1}\right\}\right] d q-C(z)
$$

The profit function of the entrant reads

$$
\pi_{1}=\frac{g a_{1}}{\gamma} \int_{0}^{\gamma} I\left[q z b-f a_{1}>\max \left\{0, q z-p-f a_{0}\right\}\right] d q-c
$$

We solve the model backwards. Given the choices by the newsmaker, if there is a market where both the news maker and the new entrant are active, the market for consumers has to be segmented because the news maker will always have greater appeal to consumers more interested in high-quality news. In the segmented market, consumers with a taste for quality in the range $q \in\left[0, \frac{f a_{1}}{z b}\right]$ will not consume any news because of the advertising involved. Consumers in the range

$$
q \in\left[\frac{f a_{1}}{z b}, \frac{p+f\left(a_{0}-a_{1}\right)}{z(1-b)}\right]
$$

will consume the entrant's product. Consumers in the range

$$
q \in\left[\frac{p+f\left(a_{0}-a_{1}\right)}{z(1-b)}, \gamma\right]
$$

will consume from the news maker.

With this in mind, the optimal choice of an entrant must solve

$$
\frac{d \pi_{1}}{d a_{1}}=\frac{g\left(\frac{p+f\left(a_{0}-a_{1}\right)}{z(1-b)}-\frac{f a_{1}}{z b}\right)}{\gamma}-\frac{g a_{1}}{\gamma} \frac{f}{z b(1-b)}=0
$$

and the entrant will only be active if profits are higher than 0 . For the news maker, the optimal choices once again involve either no advertising or zero-pricing, depending on whether $g>f$ or vice versa. The more interesting case is when there is zero-advertising for the news maker, though in reality the opposite is normally the case. Since the algebra is almost identical, we simply assume that $f>g$ in which case $a_{0}=0$ and we can write the first order conditions for the news maker in an interior solution as: 


$$
\begin{aligned}
\frac{d \pi_{0}}{d p} & =\frac{\left(\gamma-\frac{p-f a_{1}}{z(1-b)}\right)}{\gamma}-\frac{p}{\gamma} \frac{f a_{1}}{z(1-b)}=0 \\
\frac{d \pi_{0}}{d z} & =\frac{p}{\gamma} \frac{p-f a_{1}}{z^{2}(1-b)}-C^{\prime}(z)=0 \\
a_{1} & =\frac{b p}{f\left(1+2 b-b^{2}\right)}
\end{aligned}
$$

The assumptions on the convexity of $C(z)$ ensures a unique solution to these equations exist, and that the profit of the news maker increases in $c$ only via the existence or not of a competitor (once an entrant has come in, $c$ is irrelevant). The interesting aspect of the model is that it might be optimal for the news maker to deter entry by reducing price or quality. To show the flavour of the general dynamics, figures 5 and 6 give results for selected simulations of the model.

The three lines in both figures correspond to three different simulation runs where $b$ differs from low (0.2) to high (0.8). The horizontal axis measures $c$ which is reversed-spaced logarithmically, ranging from 10 to 0.001 . In Figure 5, the vertical axis is the level of quality chosen by the news maker, while in Figure 6, it shows the level of profits of the news maker. As we can see, with the Low-Copy and Medium-Copy lines, there are three distinct regions.

The first region relates to when search costs are so high that the news maker simply chooses the monopoly level of news quality without being influenced by the threat of entry. In this first region, quality is constant. The second region relates to intermediate levels of search costs where the news maker reduces the quality level (and obtains lower profits) to prevent entry. That second region is typified by gradually reducing quality levels. The third region relates to very low levels of search costs where there is a copying competitor and both quality and profit levels are low but constant. The parameter ranges have been chosen such that one can see cases where a news maker would almost immediately make negative profits as soon as the possibility of an entrant becomes salient (this the High-Copy case with $b=0.8$ ), as well as cases where a news maker continues to make positive profits but simply responds to a competitor by having lower prices (the Low-Copy and Medium-Copy cases). These simulations also show that the relationship between search costs and optimal levels of quality is not necessarily monotonic ${ }^{20}$

\footnotetext{
${ }^{20}$ We also tried endogenising $b$ by making it a function of investments in search. This makes the model analytically intractable while the simulations provide no further insights.
} 
Frijters and Velamuri: Internet and News Quality
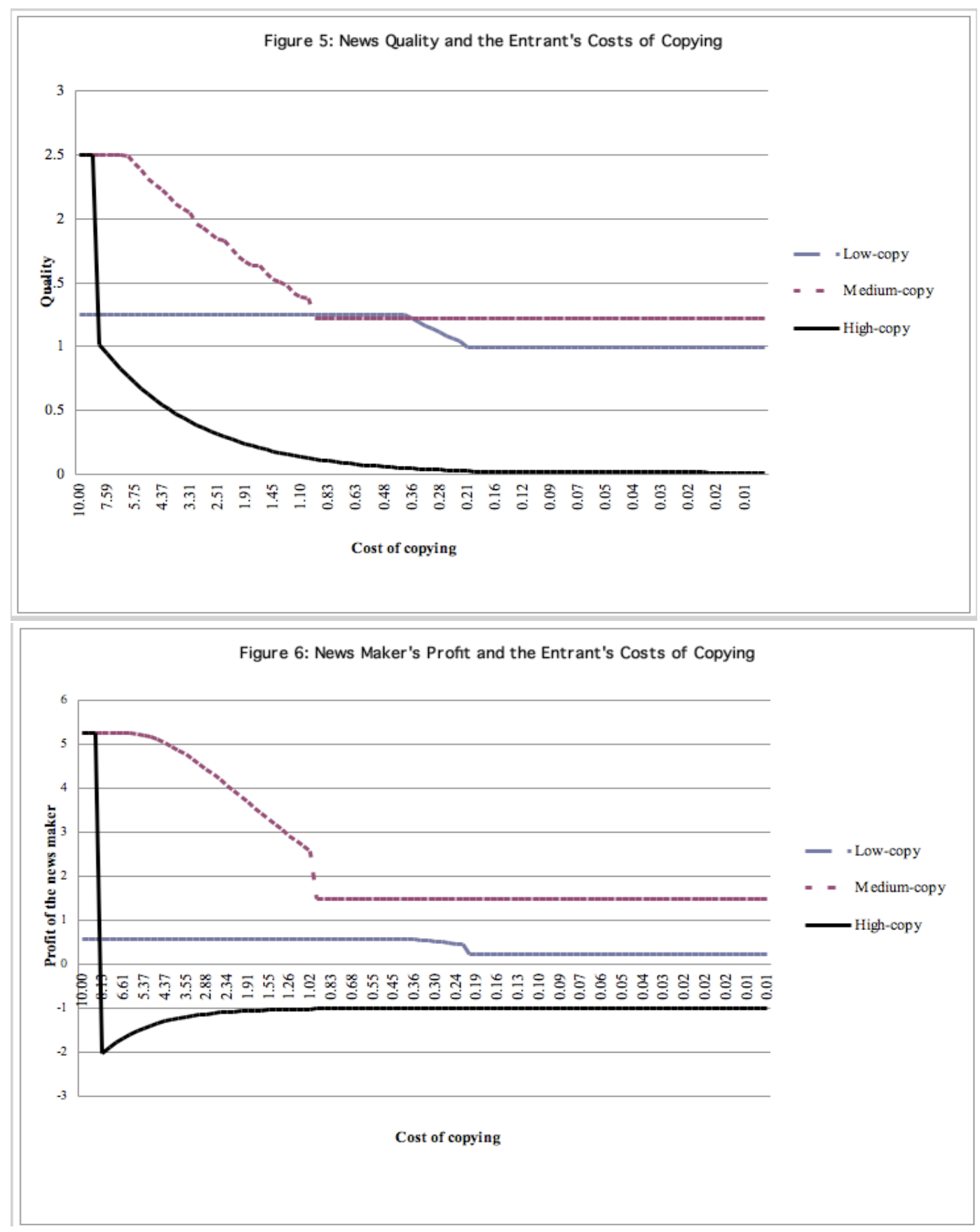

\section{Conclusions}

The effect of the internet on the provision of high-quality news has been much debated in the media itself. Bloggers have been accused of recycling the news gath- 
ered by traditional media providers, making it unprofitable for these providers to produce high-quality news in the first place. In this paper, we examine historic trends in the media industry in the U.S. and study the impact of digital technologies on the provision and uptake of high-quality news. We present a simple textbookstyle theoretical model to explain the stylized facts characterizing the media industry at present.

Our model predicts that internet-based delivery of high-quality news would only survive as an advertising-based market because reduced search costs due to the internet make it virtually impossible to capture the rents of news itself. Thus news will have to pay for itself indirectly, just as it has done in the past. Empirically, this appears to be exactly what is happening, with online news provision in the US nearly doubling in that last 4 years alone. Furthermore, specialized highquality outlets catering to specific markets have also boomed in this period (eg. the Economist, the New Yorker, National Geographic). Hence the empirical picture that emerges is the de-bundling of news: mainstream audiences get 'soft news' while individuals interested in specific news get it from specialized sources and mainly pay for it via their exposure to advertising.

One recent trend appears to go against the prediction of our model which is that some newspapers have started charging consumers for online access; while the Wall Street Journal has always charged for access to the vast majority of its online content, the Times newspaper in the UK and Le Figaro in France have recently followed suit. A number of other newspapers, both in the US and worldwide, are also debating the reintroduction of paid access. However, the Wall Street Journal's success with the paid-subscription model is attributed to its financial analysis which is considered unique and more timely than what competitors offer. Moreover, the average consumer of theWall Street Journal news is educated and has above-average earnings, making her appealing to advertisers. Unless other newspapers also offer something unique and appealing to high-income consumers, it is difficult to envisage the subscription-based model becoming the new economic model for the media industry.

It is also imporant to keep in mind that the few newspapers that charge for access still rely mainly on advertising for their revenue; what we are witnessing is more an attempt to prevent the rent-skimming associated by internet-copiers rather than getting individuals to pay for news itself. Given that the online advertising market is expected to recover and grow quickly ${ }^{21}$, it will remain the case that the online business model is advertising based. News providers will try to reduce rentskimming of news-copiers by technical and legal means, rather than demanding subscription fees from consumers.

\footnotetext{
${ }^{21}$ Analysts expect that the U.S. online advertising market will grow to between $\$ 26$ billion and $\$ 30$ billion in 2011 (Holahan, 2007).
} 
Frijters and Velamuri: Internet and News Quality

\section{References}

Bagdikian, B. (2004): The New Media Monopoly, Boston: Beacon Press.

Berry, S. and J. Waldfogel (2001): "Do mergers increase product variety? evidence from radio broadcasting," Quarterly Journal of Economics, 116, 1009-1025.

Carroll, J. (2007): "Foreign news coverage: The u.s. media's undervalued asset," Joan Shorenstein Center on the Press, Politics and Public Policy Working Paper Series Number 2007-1.

Cooper, M., G. Kimmelman, and C. Leanza (2001): "Comments of consumers union, consumer federation of america, civil rights forum, center for digital democracy, leadership conference on civil rights and media access project," http://www.consumersunion.org/telecom/fccdc1201.htm.

Dertouzos, J. and W. Trautman (1990): "Economic effects of media concentration: Estimates from a model of the newspaper firm," Journal of Industrial Economics, 39, 1-14.

Drum, K. (2007): “A blogger says: Save the msm!" http://www.motherjones.com/politics/2007/03/blogger-says-save-msm.

Einstein, M. (2004): "Broadcast network television, 1955- 2003: The pursuit of advertising and the decline of diversity," Journal of Media Economics, 17, 145155.

Filistrucchi, L. (2005): “The impact of internet on the market for daily newspapers i italy," European University Institute Working Paper No. ECO2005/12.

Fleeson, L. (2003): "Bureau of missing bureaus," American Journalism Review.

Gabszewicz, J., N. Sonnac, and D. Laussel (2006): "Competition in the media and advertising markets," Manchester School, 74, 1-22.

Gentzkow, M. (2007): "Valuing new goods in a model with complementarity: Online newspapers," American Economic Review, 97, 713-744.

Gomery, D. (2002): The FCCS Newspaper-Broadcase Cross-Ownership Rule: An Analysis, Washington D.C.: Economic Policy Institute.

Holahan, C. (2007): "The case for freeing the WSJ online," News Analysis, Bloomberg Businessweek.

Horrigan, J. (2006): "Online news: For many home broadband users, the internet is a primary news source," PEW Internet and American Life Project.

Hume, E. (1996): "The new paradigm for news," Annals of the American Academy of Political and Social Science, 546, 141-153.

Isaacson, W. (2009): "How to save your newspaper," Time Magazine.

Kaiser, U. and J. Wright (2006): "Price structure in two-sided markets: Evidence from the magazine industry," International Journal of Industrial Organization, $24,1-28$.

Langfitt, F. (2006): “"economist' magazine wins american readers,” NPR. 
Lawton, B. (2007): "Newspapers' online operations: Performance report 2006," Newspaper Association of America Report.

Lenhart, A. and S. Fox (2006): "Bloggers: A portrait of the internet's new storytellers," PEW Internet and American Life Project.

McChesney, R. (1999): “The new global media: It's a small world of big conglomerates," The Nation Magazine.

McEwen, M. (2007): "Media ownership; rules regulations and practices in selected countries and their potential relevance to canada," Report for the Canadian Radio-television and Telecommunications Commission.

Mutter, A. (2009): “Newspaper sales slid record \$7.5b in '08," Reflections of a Newsosaur Blog.

NAA (2006): "The source: Newspapers by the numbers," Newspaper Association of America Report.

Neiva, E. (1995): "Chain building: The consolidation of the american newspaper industry, 1955-1980," Business and Economic History, 24, 22-26.

Nilsson, A., U. Nuldén, and D. Olsson (2001): "Mobile media: The convergence of media and mobile communications," Journal of Research into New Media Technologies, 7, 34-38.

Nisbet, M. (2001): "How soft journalism - that offers sensationalism, celebrity, crime \& the paranormal as news - undermines the credibility of major media organizations, drives away their core audiences, and hurts democracy," Committee for Skeptical Inquiry.

Owen, B. and M. Spence (1977): "Television programming, monopolistic competition, and welfare," Quarterly Journal of Economics, 91, 103-126.

Patterson, T. (2000): "Doing well and doing good: How soft news and critical journalism are shrinking the news audience and weakening democracy-and what news outlets can do about it," John F. Kennedy School of Government Research Working Paper, RWP01-001.

PEJ (2006,2007,2008): “The state of the news media," Annual Report on American Journalism.

Peterson, P. e. (2003): "Finding americas voice: A strategy for reinvigorating u.s. public diplomacy," Report for the U.S. Council on Foreign Relations.

PEW (2006a): "Maturing internet news audience - broader than deep," PEW Research Center for the People and the Press Report.

PEW (2006b): "Online news: For many home broadband users, the internet is a primary news source," PEW Internet and American Life Project.

PEW (2007): "Views of press values and performance," PEW Research Center for the People and the Press Report.

PEW (2008): "Home broadband," PEW Internet and American Life Project. 
Reddaway, W. (1963): “The economics of newspapers," Economic Journal, 73, 201-218.

Robinson, M. (2007): “The news interest index, 1986-2007: Two decades of american news preferences, parts i and ii," PEW Research Center for the People and the Press Report.

Rosse, J. (1967): "Daily newspapers, monopolistic competition, and economies of scale," American Economic Review, Papers and Proceedings of the Seventy -ninth Annual Meeting of the American Economic Association, 57, 522-533.

Rosse, J. (1970): "Estimating cost function parameters without using cost data: Illustrated methodology," Econometrica, 28, 256-275.

Satloff, R. (2003): "How to win friends and influence arabs: Rethinking public diplomacy in the middle east," Weekly Standard.

Shah, A. (2007): "Media conglomerates, mergers, concentration of ownership," GlobalIssues.org.

Strömberg, D. (2004): "Mass media competition, political competition, and public policy," Review of Economic Studies, 71, 265-284.

UNPAN (2001): “Governance world watch,” Technical report, United Nations. 